\title{
Sobre la indeterminación en The Fall of the House of Usher
}

José M. Sardiñas

Casa de las Américas. México.

El objetivo de este comentario es analizar aspectos de la constitución de The Fall of the House of Usher, desde el punto de vista de algunas de sus indeterminaciones. Éste es un texto con muchas zonas ambiguas, razón por la cual quisiéramos observar algunas de ellas, valorar su importancia en la construcción de sentidos de la obra, y analizar cómo han intentado precisarlas algunos críticos.

Más, pues, que interpretarlo y añadir a nuestra lectura lo que juzguemos aprovechable del cúmulo de opiniones y análisis que se han vertido sobre él a lo largo de un siglo -forma en que normalmente procede uno para comentar un texto literario-, quisiéramos tomarlo como objeto de recepción virtual, tanteando parte de su estructura apelativa, y estudiar, a modo de ejemplos, algunas de las recepciones que efectivamente ha tenido entre lectores especializados como los críticos. Aunque, desde luego, esta lectura permeará inevitablemente todo el análisis.

Por otra parte, la elección de Poe obedece al hecho de que él forma parte notable de la larga historia de la estética del efecto (Wirkungsästhetik), predecesora de la estética de la recepción (Weinrich, 1993: 201), en virtud de su poética de la unity of effect.

Según esta idea, con la cual se estaba canonizando el género, todo cuento debía concebirse -y muy meticulosamente, hasta en sus detalles- en función del efecto que quisiera provocar en su desenlace. Lo que significa que debía escribirse teniendo en cuenta el modo en que esperaba ser leído, calculando cuidadosamente las reacciones posibles del lector.

Y nos centramos en The Fall of the House of Usher, en particular por la frecuencia con que la crítica se vuelve sobre este cuento, para ensayar interpretaciones. Esto es sin duda un reconocimiento de su méritos literarios; ya notaba Borges (1980: 282) que clásicas eran las obras que conservaban a lo largo del tiempo la capacidad de comunicar cosas a los hombres, y aunque éste tal vez no sea un clásico, sí es muy elocuente. Pero es sobre todo una prueba de la presencia de indeterminaciones, pues la crítica suele nutrirse de ellas.

1.

El concepto de indeterminación fue desarrollado por R.

Ingarden (1993: 32 et sqq.); W. Iser lo retomó en un artículo básico de 1975 y lo integró a otro concepto importante, y en 
esa fecha aún no muy claramente formulado, de la estética de

la recepción: el de estructura apelativa (Iser, 1993).

La indeterminación es, pues, uno de los componentes de ese "conjunto de elementos intratextuales cuya función básica consiste en exigir la participación del lector, quien de ese modo se ve apelado a completar el sentido del texto" (Vital, 1994: 21). Algunos de esos elementos son las insinuaciones, la estructura profunda de una ironía, las secuencias o escenas incompletas, los datos de referencia que piden deducción, los blancos o vacíos de información (Vital, 1994: 40), las alusiones, la llamada intertextualidad, etc.. Sin embargo, conviene distinguir, aunque sea rápidamente, la indeterminación como noción general, de términos como blanco, vacío o espacio de indeterminación, en los que Iser trabajó después de "La estructura apelativa del texto".

La noción general indica una propiedad, inherente a todo texto literario, que surge, en parte, de lo que Iser (1993: 101) denominó "la peculiaridad" de dicho tipo de texto frente a otros: aquél produce o constituye a su objeto, no representa ni comunica un objeto que exista fuera y con independencia de él. Por tanto, la posibilidad de comparar el objeto constituido con otros que pudieran ser su modelo es nula (vieja exigencia teórica, formulada por primera vez con ardor por los formalistas rusos). Lo que el texto literario dice es lo único que podemos saber, en rigor, del objeto que, a partir de sus perspectivas esquematizadas, vamos constituyendo o concretando durante el acto de lectura (Ingarden, 1993: 35-36; Iser, 1989: 150-153).

Cuán amplia pueda ser la indeterminación es algo que depende en definitiva de cuántas preguntas pueda dirigir al texto el lector, si bien muchas de ellas corren el riesgo de ser inútiles. Ningún texto puede -ni necesita- detallar todos los objetos y rasgos de objetos que virtualmente "caben" en una habitación, descrita en una novela; ninguno tampoco dispone de posibilidades para ser exhaustivo en la narración de los hechos asignables a un tramo de la vida de un personaje. "Un objeto llamado literario no alcanzaría nunca el final de sus determinaciones" (Iser, 1993: 104); mientras más se empeña en introducir precisiones, más detalles deja ambiguos o calla.

Pero la indeterminación surge también por otros motivos que Iser no menciona pero que vale la pena recordar. Uno de ellos parece ser un principio estético: la funcionalidad o pertinencia de cuanto rasgo o detalle se precisa. Normalmente suponemos que todo lo que un texto especifica tiene una intención, y ése es un presupuesto de la crítica (Freundlieb, 1982: 35). La otra motivación es deducible de lo que Iuri Tynianov denominó principio de construcción (1965: 114-119, 120-137). Según este principio, en toda obra hay una correlación jerárquica de elementos que define cuál de ellos se prioriza y cuáles se subordinan al priorizado. Como consecuencia de esa relación, muchos pueden sufrir deformaciones funcionales; una de ellas probablemente sea el quedar poco o menos determinado.

Los lugares de indeterminación, en contraste, no dependen fundamentalmente de una propiedad del código "lenguaje literario" ni de una propiedad de los textos que la manifiestan sino de una voluntad estética conformadora, subyacente en cada texto particular. Son vacíos mucho más significativos y que exigen más del lector que las indeterminaciones generales. De hecho, son los que el lector está obligado a "llenar" para dotar de coherencia y de continuidad a la historia que concreta o realiza. Y hemos puesto entre comillas el verbo llenar no por artificio retórico sino para marcar un als $o b$ tácito, porque no es ésa exactamente la operación que se espera del lector en esos casos: no se trata de que imaginemos el cabello gris, no especificado, en un texto que trate de un anciano sino de que seamos capaces de suplir relaciones no establecidas de modo explícito. Iser caracteriza así el concepto: 
En lugar de una exigencia de complementación muestran una exigencia de combinación. Pues sólo cuando los esquemas del texto son mutuamente referidos, comienza a constituirse el objeto imaginario, y esta operación solicitada del lector posee en los espacios vacíos un momento central desencadenante. Por su medio queda marcado el potencial del ensamblaje de sus segmentos en el texto, que ha sido dejado en blanco. Consecuentemente, materializan las "articulaciones del texto", pues funcionan como los "goznes pensados" de las perspectivas de aprendizajes (...) (1987: 280).

Pueden ser formas de indeterminación de este último tipo el corte argumental en un momento de suspense, la introducción de nuevos personajes y líneas de acción, los comentarios del narrador que ofrece puntos de vista divergentes, la no confiabilidad del narrador (Iser, 1993: 108-110), y las compresiones de períodos temporales o de recorridos por el espacio.

2.

En The Fall of the House of Usher hay indeterminaciones de los dos tipos. Este relato nos pone frente a un objeto que pudiéramos llamar "de pequeñas dimensiones", no ante una multitud épica ni ante un "fresco" realista. Posee una concentración apreciable de la acción en tres personajes, en un solo lugar y en un corto lapso de tiempo; comienza in medias res y apunta con varios detalles de modo directo hacia el final (Oliboni, 1986-1987: 73-74). Sin embargo, abunda en ambigüedades, como ya he dicho; algunas de ellas incluyen sucesos inexplicados que parecen apuntar hacia lo irracional, y por eso es lógico que se les intente buscar una explicación.

No aclara el texto, por ejemplo, dónde ocurren los hechos, ni en qué época. Menciona una Edad Media como pasado de la familia Usher -rasgo frecuente en la novela gótica-, y ello implica que el relato es situado en un tiempo posterior a esa época y en un espacio donde ella transcurrió, pues es sabido que ese período no es común para todos los pueblos; los nombres ingleses son otro indicio. Pero en rigor nada se dice al respecto.

Tampoco precisa el texto la causa de la atmósfera peculiar que envuelve la casa, que al parecer es objetiva (la perciben dos personajes), ni la enfermedad que padece Madeline Usher, ni lo concerniente a su muerte y conservación. Los motivos para mantenerla en un sótano antes de inhumarla tampoco convencen a los críticos, aun cuando el texto aporta varios. No obstante, en caso de aceptarlos, el texto calla acerca de la forma de conservar el supuesto cadáver, ya que la expresión utilizada sugiere que se trata exactamente de conservación ("preserving her corpse" [Poe, 1975: 240]) y el tiempo que se esperaba que éste yaciera en el sótano lo exigía forzosamente, a fin de evitar la descomposición.

Y la lista de indeterminaciones podría prolongarse más: cómo pudo una persona tan débil y enferma como Madeline romper el sello de metal con que se aseguró la puerta del sótano, por qué se selló así esa puerta (¿qué se temía?, ¿qué se prevenía?), qué grado de participación tuvo el personaje-narrador en todo ello, por qué mueren simultáneamente los hermanos, por qué coincide esa muerte con el hundimiento de la casa, qué relación guarda el poema de Roderick con el resto de la historia, etc.

Pero añadir más ejemplos de zonas imprecisas sólo serviría para mostrar que el 
texto acumula una cantidad suficiente de indeterminaciones como para dar resultado, durante el proceso de concreción, a la constitución de una obra con múltiples intersticios entre las perspectivas esquematizadas (Iser, 1989: 149). Cuáles de ellos pueden necesitar llenar un lector real cualquiera para sentir que el texto es coherente, y cuáles pueden quedar en su estado, sin provocar inquietud, es lo que trataremos de analizar a continuación.

Para comenzar por una categoría textual de primer orden, es poco lo que sabemos del narrador-personaje. Son más los datos que deducimos de sus comentarios y acciones (formas de caracterización indirecta) que los que él expresamente nos da de sí. Incluso la atribución de género es durante un buen trecho una operación lógica no lingüística: toda vez que la lengua inglesa carece de desinencias de género en adjetivos, participios, etc., lo inferimos del hecho extratextual de que en los cuentos de Poe normalmente narra un hombre, y del otro, intratextual pero sustentado en una costumbre -en un elemento cultural y por ende referencial-, de que la entidad que narra dice andar sola y a caballo: "I had been passing alone, on horseback” (Poe ,1975: 231). De esta forma no solían viajar más que hombres. Sólo después aparece la marca de género ("Its proprietor, Roderick Usher, had been one of my boon companions in boyhood"; "Although, as boys, we had been...", (Poe, 1975: 232. El destacado es nuestro).

Pero éste es un rasgo no esencial, por lo menos desde el punto de vista narratológico. Es una indeterminación que no indica una ausencia significativa. El que sepamos poco del narrador no quita credibilidad a su historia, del mismo modo que no se la conferiría una serie de datos sobre sí, a menos que hubiera elementos que dirigieran la atención del lector hacia su credibilidad, y no parece ser el caso. Hay, en cambio, otras indeterminaciones, también concernientes al narrador, cuyo grado de relevancia es más dudoso: su relación con Roderick Usher, por ejemplo.

En ese lento acercamiento al protagonista que se da por grados, en una secuencia que va desde planos muy generales hasta el primer plano, revelando "semelhanças com o movimento da câmera" (Oliboni, 1986-1987: 74), el narrador tiene ocasión de informar que es un viejo amigo de infancia del protagonista, a quien desde hace mucho no ve y nunca llegó a conocer profundamente, a pesar de lo cerca que estuvo de él: "Although, as boys, we had been even intimate associates, yet I really knew little of my friend. His reserve had been always excessive and habitual" (Poe, 1975: 232). Es todo cuanto dice del vínculo que ha mantenido con Roderick (más bien caracteriza psicológicamente a su amigo).

Uno puede entonces preguntarse por qué Roderick llama precisamente a alguien tan distante cuando necesita compañía. Conociendo el grado de aislamiento en que vive, es de suponer que no tenía muchas personas a quienes acudir por ayuda. Pero aun así, su proceder resulta poco convincente. Acaso no haya otra explicación que el tratarse de otra rareza de una personalidad poco común.

Sin embargo, una crítica, Cynthia S. Jordan, detecta una relación que, por lo menos en principio, el texto no parece acentuar muy particularmente. C.S. Jordan presta atención enfáticamente a las relaciones de géneros y aun de sexos, en consonancia con la metodología feminista que sigue, y encuentra una "homoerotic attraction" en el narrador hacia el amigo (Jordan, 1987: 8).

Jordan establece nexos de carácter simbólico entre componentes espaciales y sexos, prolongando de esta forma la caracterización metonímica del espacio que también otros críticos (Oliboni, 1986-1987: 74) han observado:

The "vacant and eye-like windows" (...), the "fine tangled web-work" of fungi "hanging... from the eaves" (...), and the crack which runs from roof to foundation prefigure Roderick's "luminous" eyes, his hair of a more than web-like softness and tenuity (...), and his oddly 
split personality, all of which seem ominous enough to the narrator. But he experiences "a shudder even more thrilling than before" when he looks at the reflection of the House in the tarn, the "remodelled and inverted images" (...) which represent Madeline, Roderick's physical and psychological counterpart (Jordan, 1987: 6-7).

Las razones que da para esta equivalencia tan unívoca y segura atañen a Madeline: ella no habla en el texto, más bien ha sido silenciada por su condición de mujer, y el estanque es también silencioso ("silent tarn", escribe Poe, 1975: 233). Ella está enferma, y su mal arrastra de alguna forma a su hermano, cosa verificable textualmente; también el estanque es descrito como un lugar de muerte -rasgo que se comprueba revisando el campo semántico con que es referido, aunque la autora no repare en ello- ${ }^{1}$. Finalmente, "she will be buried at a 'great depth' (...) in the House, in a chamber that lies beneath the surface of the tarn and of the narrative" (Jordan, 1987: 7).

Pero en cuanto a la forma de asociar a Roderick con la mansión, no da argumentos. Combina elementos de este relato con los de otros "woman-centered tales" para concluir que, como la composición de la balada de Roderick "is reminiscent of Morella and Ligeia, who had been characterized by their musical language", y como "Poe's physical description of Roderick is in fact (...) very similar to that of the beautiful Ligeia" (Jordan, 1987: 9), el protagonista de nuestro cuento reúne rasgos femeninos. Éstos coexisten con otros que, de acuerdo con los papeles que la cultura ha asignado a los sexos, Jordan lee como masculinos; tales la actividad y la energía.

Y así, interpreta la figura de Roderick como la de un andrógino en quien toma cuerpo un supuesto conflicto entre el narrador y el personaje femenino. El narrador, llamado por el protagonista y unido a él por atracción sexual, rechaza el lado femenino que Roderick muestra y quisiera mantener con él una relación que excluye a la mujer en absoluto (al punto de ayudar a sepultarla viva).

Una prueba posible de ello es -siempre de acuerdo con la crítica- esa especie de acto fallido que comete el narrador al decir que fue despertado, la noche final, por un íncubo en lugar de por un súcubo. Con esto, el autor pareciera sugerir que el narrador se siente tan atraído por la parte viril que, inconscientemente, se ve a sí como mujer visitada por un demonio varón: “...Poe would seem to be suggesting that the narrator's homoerotic attraction to Roderick has caused him to see himself in some way feminized" (Jordan, 1987: 8).

Ahora bien, tomando esta probabilidad con todas las precauciones que impone la ambigüedad de la palabra íncubo desde hace siglos ${ }^{2}$, retomemos el punto de partida de esta indeterminación: ¡es de carácter general, o marca por el contrario un vacío generador de significaciones implícitas? O dicho de otra forma: ¡es de las que es inútil llenar o de aquellas que el texto pide que se llenen como condición para lograr una comprensión?

Evidentemente, para C.S. Jordan es de las segundas porque, entre otras cosas, le permite hablar de un "eminently unreliable narrator" (1987: 11), y una voz narrativa con esa condición abre grandes posibilidades de interpretación (como no es de confiar, todo lo que diga puede ser sometido a discusión). Pero hay razones que sustentan la opinión contraria, aun soslayando diferencias de puntos de vista teóricos.

Decidir si una indeterminación es irrelevante implica tener una visión clara de las perspectivas que el texto ofrece y esto, en verdad, es un proceso altamente subjetivo que diferirá de un lector a otro. No obstante, hay algunos elementos dignos de atención, si se trata de situarse en el lugar que el texto sugiere como idóneo para ser leído: el título, el epígrafe, las dedicatorias, etc.; todo aquello que Genette denomina enunciados paratextuales lato sensu y que, sobre todo en el caso de los dos primeros enumerados, contienen pautas de lectura (Genette, 1987: 8). Sin embargo, la profesora Jordan no repara en esto en ningún punto de su amplia interpretación. 
Para ir directamente al enunciado que me parece más significativo, el epígrafe de este relato, "Son coeur est un luth suspendu;/ Sitôt qu'on le touche il resoné", puede entenderse como una alusión a un tipo de relación humana en que una persona, más que accionar, reaccione a los impulsos de otra (el corazón resuena cuando es tocado). $Y$ en vista de que aquí la participación del narrador como personaje es más bien secundaria, de testigo que cuenta lo que ocurrió a otros en su presencia, suponer que el epígrafe pueda referirse a él y al protagonista sería forzar las cosas. Contrariamente, Madeline podrá no hablar en el texto pero su función es a todas luces más importante en el desarrollo de la trama: es quien sostiene y desencadena el conflicto que da vida a la narración (y ya se sabe que un relato sin conflicto no es ni siquiera narración, ya no digamos cuento).

Por tanto, es a ella a quien debe de aludir el tipo de relación sugerido por el epígrafe. La relación entre ella y su hermano debe de ser uno de los ejes de sentido del texto, y es hacia ahí adonde se supone que el texto pida más atención. Así, pues, si es aceptable la lectura que hice del principio de construcción de Tynianov, las demás relaciones -incluida en ellas la del protagonista con su amigo- son de un rango menos importante en este cuento y pueden experimentar como deformación una indeterminación de carácter general.

Desde luego, no es posible ignorar que lo que juzgo es el resultado de que no se haya reparado en el epígrafe. El que la autora comentada hubiera recurrido a él no garantizaría en modo alguno la coincidencia, en relación con la clase de las indeterminaciones, ni tampoco respecto a la captación de las perspectivas esquematizadas. Pero tampoco es legítimo desconocer textos como los epígrafes, que no sólo son componentes de ese signo complejo que es toda obra, sino componentes particularmente significativos (Genette, 1987: 145-149).

Como hemos visto, el tipo de relación de los hermanos parece ser el núcleo de significación de este texto. Ello no es óbice, sin embargo, para que constituya también una de sus zonas de indeterminaciones. Y en esta ocasión sí es posible adelantar que se trata de lugares intencionalmente imprecisos. Es probable que un indicio de ello sea la variedad de interpretaciones plausibles que admite, apoyadas en esquemas de conocimiento ("knowledge frames", Freundlieb, 1982: 26) a veces alejados entre sí.

Todo cuanto dice el texto del particular es que ambos personajes son hermanos gemelos, los últimos de una antigua familia, que están enfermos, que habitan solos (sin otra compañía que la de algún ujier) la vetusta mansión, y que se tienen un afecto que el texto da pie para considerar peculiar; por lo menos Roderick profesa ese tipo de cariño a su hermana. De acuerdo con lo que afirma el narrador, aun el estado de deterioro mental del protagonista tiene como causa la enfermedad de su "tenderly beloved sister":

He admitted, however, although with hesitation, that much of the peculiar gloom which thus afflicted him could be traced to a more natural and far more palpable origin -to the severe and long-continued illness-indeed to the evidently approaching dissolution -of a tenderly beloved sister... (Poe, 1975: 235-236).

El texto no va más allá, de manera explícita. Sin embargo, Tzvetan Todorov parece detectar un vínculo incestuoso entre ambos personajes. Todorov utiliza nuestro texto como exponente de su concepto de lo extraño, es decir, del acontecimiento sobrenatural explicado de modo racional. Observa que, en éste, lo extraño tiene dos fuentes: las coincidencias y la experiencia de los límites. Y ofrece una coincidencia: "la résurrection de la soeur et la chute de la maison après la mort de ses habitants" (1970: 53), cuyas explicaciones radican en la catalepsia y en la fisura de la casa. En cuanto a la experiencia de los límites, asevera que es el estado extremadamente enfermizo de los hermanos lo que turba al lector (1970: 53) y añade, 
precisando la causa de ese efecto, tras evocar a Freud, que "le sentiment d'étrangeté part donc des thèmes évoqués, lesquels sont liés à des tabous plus ou moins anciens" (1970: 53-54). No menciona el incesto pero lo alude cuando habla de tabús en relación con el fundador del psicoanálisis.

Por otra parte, D. Freundlieb comprende las peculiares relaciones de Roderick y Madeline como una manifestación, entre otras que contiene el texto, de las fuerzas de atracción y repulsión que gobiernan el cosmos, según la teoría expuesta por Poe en Eureka: "Poe's cosmology -asevera- permits the reader to explain events, actions and the whole episodes as effects of the interaction of the two basic forces of attraction and repulsión" (1982: 38).

La sensibilidad hiperestésica que permite al protagonista escuchar de lejos los ruidos más secretos de su hermana, incluso los de su fisiología, es una manifestación de la repulsión. El hecho mismo de que él la haya sepultado viva, a sabiendas, era un esfuerzo por detener una unión de cuerpos que acabaría por ocasionarle la muerte, y no por la maldición que la transgresión simbólica de un tabú atraería sobre sus cabezas sino por ser una consecuencia de la fuerza de atracción: "Every attempt at approximations of two bodies as an effect of attraction leads to an increase in repulsion in order to prevent, at least temporarily, the contact and final coalition of matter" (Freundlieb, 1982: 39).

Luego, tanto el abrazo mortal como el hundimiento de la casa son formas mediante las cuales "the phase of increasing and accelerating contraction" (Freundlieb, 1982: 38) que vive el Universo deja sentir su influencia. Dicha fase aparece descrita en Poe como un período de colapso, como un proceso inverso hacia el "original state of absolute unity and non-materiality" (Freundlieb, 1982: 37).

De acuerdo, pues, con esta interpretación, los hermanos interactúan porque están unidos por destino, porque son instrumentos de fuerzas que los rebasan, del mismo modo en que rebasaban al barón de Metzengerstein y al conde Berlifitzing en "Metzengerstein" (Freundlieb, 1982: 41).

Finalmente, tampoco sería descabellado pensar en una relación de dependencia parapsicológica, teniendo en cuenta elementos como el epígrafe, ya comentado brevemente; la actitud receptiva, de escuchar como hipnotizado los sonidos que suben desde el sótano, y reactiva, frente al grito de Madeline, que adopta Roderick la noche de la tormenta; la forma también reactiva en que él muere, y la condición de hermanos gemelos de estos personajes, entre quienes existía no sólo una "striking similitude", sino también "sympathies of a scarcely intelligible nature" (Poe, 1975: 240).

La parapsicología no es infrecuente en la literatura fantástica-extraña, a la que The Fall... pertenece; aquélla, como el mesmerismo y la frenología, forma parte de la llamada red temática del "yo" (Todorov, 1970: 113 et sqq.), característica de ese género, y que agrupa fenómenos anómalos de percepción de la realidad.

De acuerdo, pues, con esta lectura, Roderick enferma más a medida que su hermana se extingue, puede escuchar durante días sonidos ("yes, I hear it, and have heard it. Long-long-long-many minutes, many hours, many days, have I heard it" [Poe, 1975: 244]) que el narrador empieza a oír sólo cuando son tan altos que compiten con los del viento y, finalmente, muere frente a Madeline porque entre ambos existe una comunicación extrasensorial probablemente involuntaria y una dependencia atípica, en las cuales él toma parte como receptor, como individuo paciente. Un hermano gemelo no puede morir sin que ello cause efectos en el otro ${ }^{3}$. 
3.

De este modo, después de haber enumerado o comentado una serie de indeterminaciones presentes en The Fall of the House of Usher, es posible intentar reunir algunas reflexiones, de carácter general, dispersas en el trabajo.

Acaso la primera y más obvia sea que, entre tantas indeterminaciones, unas obedecen a rasgos inherentes a todo texto literario, y otras a marcas virtuales de intención del autor implícito. Decidir cuándo estamos ante una de éstas y cuándo ante una de aquéllas no siempre es factible con el mismo grado de seguridad. Identificarlas -no importa de qué tipo sean- es una operación posterior, por lo menos lógicamente, a la de haber identificado esas guías del lector que son las perspectivas. Esto, a su vez, es un proceso complejo y subjetivo.

Semas textuales como los que ha estudiado Genette (1977) sin duda sirven de orientación, aun cuando no conduzcan a todo lector al mismo sitio (lo cual es imposible, tratándose de códigos ambiguos como la lengua y los diferentes lenguajes literarios de géneros, corrientes, individuos, etc.). Sin embargo, es preciso tomarlos en consideración.

Por otra parte, y aunque no hemos reseñado en su totalidad las críticas a las que hiciéramos referencia, creemos que con lo comentado puede verse que no siempre los críticos están tan conscientes de la operación hermenéutica que realizan, como sería deseable. No siempre parten del presupuesto de que cuando interpretan, lo que realmente hacen es construir discursos propios precisamente sobre los lugares imprecisos de un texto, sobre sus vacíos, y no descubrir discursos existentes de manera implícita (Freundlieb, 1982: 36).

Contrariamente a quienes, como el propio Iser (1993: 99) y D. Freundlieb (1982: 25), han propugnado casi por la abolición de las interpretaciones en favor de otras estrategias críticas, somos del criterio de que las interpretaciones tienen un valor digno de consideración. Pero no creemos conveniente que no se formulen sin mostrar sus puntos de partida más elementales porque contribuyen a canonizar lecturas que, por más autorizadas, no dejan de ser personales y, sobre todo resultados, de un lector entre otros.

\footnotetext{
${ }^{1}$ En relación con el estanque se usan expresiones como black, lurid, unruffled lustre, silent, sullen, dim, still, rank miasma y dank, que indican carencia de vida, estatismo.

${ }^{2} \mathrm{Si}$ bien es cierto que a lo largo del tiempo se ha intentado mantener la oposición, justificada por razones etimológicas, entre "íncubo" y "súcubo", y que de hecho se ha mantenido en la mayoría de los casos, no lo es menos que ha habido vacilación en el uso, y que el primer término ha cubierto a veces el campo semántico del segundo, deshaciendo la oposición; así, por ejemplo, Guazzo, en su Compendium maleficarum (1608), escribía: "[The incubus] can assume either a male or a female shape; sometimes he appears as a full-grown man, sometimes as a satyr; and if it is a woman who has been received as a witch, he generally assumes the form of a rank gota" (Hope, 1981: s.v. "incubus": 254). Por otra parte, "íncubo" ha significado también pesadilla o sueño
} 
de contenido erótico en general: "Inasmush as the night-mare dream is sexual in latent content, incubus is often used interchangeably with the mare demon" (Hope, 1981: 254).

${ }^{3}$ Detrás de esta creencia se halla un valor simbólico bastante generalizado entre varias mitologías, que asigna a los gemelos la calidad de dualidad en la unidad: "dans toutes les traditions, des jumeaux, dieux ou héros, se querellent ou s'entraident, marquant ainsi la l'ambivalence de leur situation, symbole de la situation même de chaque être humain divisé en lui-même” (Chevalier, 1982: s.v. “jumeaux”: 546).

\section{Bibliografía}

Borges, J.L. (1980), "Sobre los clásicos”, en Nueva antología personal, Barcelona, Bruguera.

Chevalier, J. (1982), Dictionnaire des symboles. Mythes, rêves, coutumes, gestes, formes, figures, couleurs, nombres, Paris, Robert Laffont/Jupiter.

Freundlieb, D. (1982), “Understanding Poe's Tales: A Schema-Theoretic View”, en Poetics (La Haya), 11, p.p. 25-44.

Genette, G. (1987), Seuils, Paris, Éditions du Seuil.

Hope Robbins, R. (1981), The Encyclopedia of Witchcraft and Demonology, New York, Bonanza Books.

INGARDEN, R. (1993), “Concretización y reconstrucción”, trad. S. Franco, en Dietrich Rall (comp.) En busca del texto. Teoría de la recepción literaria, México, UNAM, p.p. 31-54.

IsER, W. (1987), El acto de leer. Teoría del efecto estético, Madrid, Taurus. Trads. J.A. Gimbernat y M. Barbeito.

(1989), "El proceso de lectura. Una perspectiva fenomenológica" en Rainer Warning (comp.) Estética de la recepción. Trad. R. Sánchez Ortiz de Urbina, Madrid.,Visor, pp. 149-164.

(1993) “La estructura apelativa de los textos", en Dietrich Rall (comp.) En busca del texto. Teoría de la recepción literaria, México, UNAM 99-119. Jordan, C.S. (1987), "Poe’s Re-Vision: The Recovery of the Second Story", en American Literature (Durham) p. 59: 1-19.

Oliboni, M. (1986-1987), "Fricção, fissura e queda da Casa de Usher" en Revista de Letras (São Paulo), p.p. 26-27: 73-78.

Poe, E. (1975), The Complete Tales and Poems of Edgar Allan Poe, New York, Vintage Books.

Todorov, T. (1970), Introduction à la littérature fantastique, Paris, Éditions du Seuil.

Tynianov, I. (1965), "La notion de construction" y "De l'évolution littéraire” en Tzvetan Todorov (comp.) Théorie de la littérature, Paris, Éditions du Seuil.

VITAL, A. (1994), El arriero en el Danubio. Recepción de Rulfo en el ámbito de la lengua alemana, México, UNAM.

Weinrich, H. (1993), "Para una historia literaria del lector" en Dietrich Rall (comp.) En busca del texto. Teoría de la recepción literaria, México, UNAM, p.p. 199-210. 